\title{
Abnormalities in the flow-volume loop in obstructive sleep apnoea sitting and supine
}

\author{
ERIC T SHORE, RICHARD P MILLMAN \\ From the Cardiovascular-Pulmonary Division, Department of Medicine, Hospital of the University of \\ Pennsylvania, Philadelphia, USA
}

\begin{abstract}
We evaluated the effect of posture on the sensitivity and specificity of abnormalities in the flow-volume loop in 30 patients with suspected obstructive sleep apnoea. Flow-volume loops were judged as abnormal if the $\mathrm{FEF}_{50} / \mathrm{FIF}_{50}$ ratio was greater than 1 or if the sawtooth sign was judged to be present by at least two of three chest physicians. Detailed nocturnal recordings confirmed the presence of obstructive sleep apnoea in 17 of the 30 patients. Our results showed that both the sensitivity and the specificity of each of the flow-volume criteria for the diagnosis of obstructive sleep apnoea were higher when the loops were recorded in the supine than when they were recorded in the sitting position. The sensitivities were low, however, even with the supine posture-sawtoothing $41 \%$ and $\mathrm{FEF}_{50} / \mathrm{FIF}_{50}$ ratio greater than $147 \%$. The highest sensitivity (71\%) was obtained by considering a positive result as being the presence of either of the abnormalities in either the sitting or the supine posture. This sensitivity of the flow-volume loop was too low to recommend it as a routine screening test for the diagnosis of obstructive sleep apnoea but the presence of the sawtooth sign had a high specificity (92\%) for the diagnosis of obstructive sleep apnoea. Furthermore, there was a greater fall in oxygen saturation in patients with apnoea who had sawtoothing than in those without sawtoothing. The presence of the sawtooth sign should increase the suspicion of sleep apnoea and suggest the need for further investigation. The effect of posture on the occurrence of abnormalities in the flow-volume loop suggests that position alters the configuration of the upper airway.
\end{abstract}

With the increasing recognition of sleep apnoea, there have been attempts to develop an inexpensive and accurate screening test which would aid in identifying subjects who require extensive polysomnographic evaluation. One test which has been used in this way is the flow-volume curve $e^{1-6}$ and one particular abnormality which has been found in obstructive sleep apnoea is "sawtoothing."' Although in the original description a very high sensitivity and specificity of this abnormality were reported, ${ }^{2}$ results of more recent studies have been less encouraging. ${ }^{3-6}$ The present study was undertaken to investigate whether this and other changes in the flowvolume loop are found more commonly in patients with obstructive sleep apnoea when supine. We argued that, particularly in obese subjects, the upper

Address for reprint requests: Dr Richard P Millman, 3 White Building, Cardiovascular-Pulmonary Division, Hospital of the University of Pennsylvania, 3600 Spruce Street, Philadelphia, PA 19104, USA.

Accepted 14 May 1984 airway may be more narrowed in the supine than in the sitting posture; narrowing of the upper airway in the supine posture alone has been demonstrated in subjects with obstructive sleep apnoea by means of computed tomography of the pharynx. ${ }^{47}$

\section{Methods}

The subject population consisted of 31 patients (23 male and eight female) evaluated consecutively at the Hospital of the University of Pennsylvania for the presence of sleep apnoea syndrome. Since the study was devised to investigate the value of flowvolume loops in the diagnosis of obstructive sleep apnoea, one man who proved to have pure central sleep apnoea was excluded.

Initially, a brief history was obtained from each patient and physical examination was performed. The height and weight of each subject were recorded and particular attention was paid to possible causes of upper airway obstruction, such as 
enlarged tonsils, macroglossia, or micrognathia.

In all subjects flow-volume loops were recorded in the sitting and supine positions (with no head support), an Ohio 840 rolling seal spirometer being used. Tests were repeated until two acceptable curves were obtained in each position, an acceptable result being defined as one in which the forced inspiratory vital capacity (FIVC) was greater than $90 \%$ of the forced expiratory vital capacity (FVC). The highest forced expiratory volume in one second $\left(\mathrm{FEV}_{1}\right)$, FIVC, and highest FVC were recorded in both the sitting and the supine positions. The ratio of the expiratory airflow during forced expiration at $50 \%$ of the vital capacity $\left(\mathrm{FEF}_{\mathbf{5 0}}\right)$ to the forced inspiratory flow at the same lung volume $\left(\mathrm{FIF}_{50}\right)$ was also measured from each of the acceptable flowvolume curves. An average of the two maximal $\mathrm{FEF}_{\text {so }} / \mathrm{FIF}_{\text {so }}$ ratios in each position was then calculated. A ratio of greater than one in either the sitting or the supine posture was considered suggestive of upper airway obstruction; ${ }^{8}$ this ratio is heavily biased towards a diagnosis of variable rather than fixed obstruction. Peak expiratory flow was greater than $31 \mathrm{~s}^{-1}$ in all subjects and peak inspiratory flow greater than $31 \mathrm{~s}^{-1}$ in all but two subjects.

The flow-volume loops in both postures were also examined for the presence of the so called sawtooth pattern. The loops were assessed independently by three pulmonary physicians who were familiar with the criteria for sawtoothing and who were unaware of the results of the sleep studies. The sawtooth pattern was considered to be present on a flow-volume loop if at least two of the three readers reported its presence.

Finally, polysomnography was performed on each subject in our sleep laboratory, and the data were recorded on a Grass EEG polygraph (Model No 78, Grass Instruments Company, Quincy, Massachusetts). Thoracoabdominal movements were assessed qualitatively with a pneumograph (Model PE-3 volumetric pressure transducer) around the upper abdomen. Airflow was measured with thermistors (Grass TLT-IR) placed at the mouth and nose. Electro-oculogram, electromyogram, and electroencephalogram were recorded continuously on the polygraph record. An ear oximeter (Model No 47201A, Hewlett-Packard, Waltham, Massachusetts) was used to measure oxygen saturation. Twenty one of the 30 sleep studies performed were all night studies. The remaining nine patients were studied during daytime sleep. Of these nine, seven had results indicating obstructive sleep apnoea; both negative daytime studies included all stages of sleep.

Data from the sleep studies were analysed according to the criteria of Block et al. ${ }^{9}$ The apnoea index was defined as the number of episodes of apnoea per hour. The severity of oxygen desaturation during the sleep study was expressed as the fall in oxygen from the baseline to the nadir $\left(\Delta \mathrm{SaO}_{2} \%\right)$. Sleep stages were classified according to the standard system described by Rechtschaffen and Kales. ${ }^{10}$

On the basis of the results of polysomnography patients were divided into two groups, those with and those without sleep apnoea syndrome. The effect of posture on FVC, FEV/FVC, FIVC, and $\mathrm{FEF}_{s 0} d \mathrm{FIF}_{s 0}$ ratio was then investigated in each group. To determine the significance of such changes, we used Student's $t$ test for unpaired or paired variables. We also examined the effect of posture on the sensitivity and specificity of an abnormal $\mathrm{FEF}_{50} / \mathrm{FIF}_{50}$ ratio and on the presence of the sawtooth pattern in predicting patients who proved to have obstructive sleep apnoea. Sensitivity, specificity and positive predictive value were calculated as:

$$
\text { Sensitivity }=\frac{\text { true positive results }}{\text { total patients with disease }}
$$

Specificity $=\frac{\text { true negative results }}{\text { total patients without disease }}$

$\begin{aligned} & \text { Positive predictive } \\ & \text { value }\end{aligned}=\frac{\text { true positive results }}{\text { total positive results }}$

\section{Results}

Twenty eight of the 30 subjects had at least two of the symptoms of snoring, frequent arousals, excessive daytime somnolence, and morning headaches, which prompted evaluation for obstructive sleep apnoea, and this was demonstrated in 17 of the 30 patients studied. Two of the 17 patients with sleep apnoea were female and 15 were male. There were 13 patients in whom sleep apnoea was not confirmed and of these six were female and seven were male. In the patients with sleep apnoea, the mean apnoea index was 45 episodes of apnoea per hour (range of $10-118)$. All these patients had greater than $60 \%$ obstructive episodes. There was no significant difference in age between the patients with sleep apnoea (mean 49.5 (SE 3.5) years) anose without $(51.5(2.4)$ years). Height was also not significantly different in the two groups (174 (2.5) $\mathrm{cm}$ and $171(3) \mathrm{cm})$, but the patients with sleep apnoea had a significantly greater body weight (129 $(10.2) \mathrm{kg}$ ) than those without $(96.3(13.4) \mathrm{kg}$; $\mathrm{p}<0.05)$. Four patients with sleep apnoea and one without had enlarged tonsils.

In both the group of patients with obstructive sleep apnoea and the group without sleep apnoea 
Table 1 Results of pulmonary function studies (means with standard errors in parentheses) in the sitting and supine posture in patients with and without obstructive sleep apnoea

\begin{tabular}{|c|c|c|c|c|c|c|}
\hline Group of patients & & $F V C(l)$ & $F E V_{1}(l)$ & $F E V, / F V C(\%)$ & $F I V C(l)$ & $F E F_{s 0} / F I F_{s 0}$ \\
\hline \multirow{2}{*}{$\begin{array}{l}\text { With obstructive sleep } \\
\text { apnoea }(n=17)\end{array}$} & Sitting & $3.74(0.252)^{* *}$ & $2.54(0.192)^{* *}$ & $73.3(2.68) \mathrm{NS}$ & $3.37(0.240)^{* *}$ & $1.09(0.177)^{*}$ \\
\hline & Supine & $3.32(0.226)$ & $2.40(0.170)$ & $71.6(2.48)$ & $3.26(0.223)$ & $1.01(0.145)$ \\
\hline \multirow{2}{*}{$\begin{array}{l}\text { Without obstructive } \\
\text { sleep apnoea }(n=13\end{array}$} & Sitting & $3.25(0.373)^{* *}$ & $2.54(0.328)^{* *}$ & $78 \cdot 1(2.95) \mathrm{NS}$ & $3.07(0.364)^{* *}$ & $1.00(0.209) \mathrm{NS}$ \\
\hline & Supine & $3 \cdot 11(0.367)$ & $2.34(0.322)$ & $74 \cdot 2(3 \cdot 15)$ & $2.99(0.387)$ & $0.841(0.121)$ \\
\hline
\end{tabular}

Comparison of changes between sitting and supine postures (paired $t$ test): ${ }^{* *} p<0.01 ;{ }^{*} p<0.05$; not significant (NS)-p $\geqslant 0.05$.

FVC-forced vital capacity; FIVC-forced inspiratory vital capacity; FEF $s d F^{\prime} F_{s \sigma}$-ratio of forced expiratory to forced inspiratory flow, both at $50 \%$ of the vital capacity.

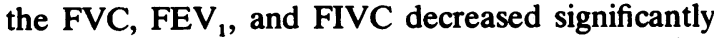
when subjects changed from the sitting to the supine posture $(\mathrm{p}<0.01)$ (table 1$)$. The ratio of $\mathrm{FEV}_{1}$ to FVC did not change significantly in either group. In the subjects without sleep apnoea the $\mathrm{FEF}_{\mathrm{so}} / \mathrm{FIF}_{\mathrm{so}}$ ratio showed no significant change with position, while in subjects with sleep apnoea this ratio decreased slightly but significantly, from $1 \cdot 09(0 \cdot 18)$ in the sitting posture to $1.01(0.5)$ in the supine posture $(p<0 \cdot 05)$. There were no differences in

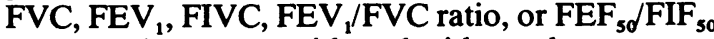
between the groups with and without sleep apnoea in either the sitting or the supine posture.

When the data in individual subjects were examined, an $\mathrm{FEF}_{\mathbf{s}} / \mathrm{FIF}_{\mathbf{s 0}}$ ratio of greater than 1 , which is suggestive of upper airway obstruction, was observed in the sitting posture in seven of 17 patients with sleep apnoea (sensitivity $41 \%$ ) and in eight of 17 in the supine posture (table 2). These eight patients included six with $\mathrm{FEF}_{s 0} \mathrm{FIF}_{50}$ ratios of greater than 1 in both supine and sitting postures and two with ratios greater than 1 in only the supine posture. Measurements in the supine posture only marginally increased the sensitivity of $\mathrm{FEF}_{s 0} / \mathrm{FIF}_{\mathbf{s}}$ greater than 1, but they reduced the number of false positive results from four to two and therefore increased the predictive value of a positive result from $64 \%$ to $80 \%$ (table 2 ). If we combined the patients with ratios greater than 1 in either the sitting or the supine position the sensitivity was $53 \%$; but the number of false positive results also increased, so that there was a fall in specificity $(62 \%)$ and predictive value of a positive result (64\%).

A total of 60 flow-volume loops were examined (30 sitting, 30 supine). In 32 there was no sawtoothing seen by any of the readers, and in 28 its presence was reported by one or more readers. The flow-volume loop was read as positive for sawtoothing by all three physicians on nine occasions and eight of these results were true positives - that is, the subjects had obstructive sleep apnoea. On six occasions only two physicians reported a positive result and four of these were true positives. Thus our criterion for a positive result-that is, sawtoothing reported as present by at least two of the three physicians-produced 12 true positive and only three false positive results. When only a single physician read the flow-volume loop as positive (which happened in 13 cases) six were true positives and seven false positives. The sensitivity and specificity of the sawtooth pattern in the diagnosis of obstructive sleep apnoea are shown in table 2. Sawtoothing was judged to be present on the flow-

Table 2 Sensitivity, specificity, and positive predictive value of abnormalities of the flow-volume loop in the diagnosis of obstructive sleep apnoea

\begin{tabular}{|c|c|c|c|c|c|c|c|c|c|}
\hline & \multicolumn{3}{|c|}{$F E F_{s 0} / F I F_{s 0}>1$} & \multicolumn{3}{|c|}{ Sawtoothing* } & \multicolumn{3}{|c|}{$\begin{array}{l}F E F_{s 0} / F I F_{s 0}>1 \\
\text { and/or sawtoothing }\end{array}$} \\
\hline & Sitting & Supine & Combined $\dagger$ & Siting & Supine & Combined $\dagger$ & Sitting & Supine & Combined $\dagger$ \\
\hline \multirow{2}{*}{$\begin{array}{l}\text { Sensitivity }(\%) \\
\text { Specificity }(\%) \\
\text { Positive predictive } \\
\text { value (\%) }\end{array}$} & $\begin{array}{l}41 \\
69\end{array}$ & $\begin{array}{l}47 \\
85\end{array}$ & $\begin{array}{l}53 \\
62\end{array}$ & $\begin{array}{l}29 \\
85\end{array}$ & $\begin{array}{l}41 \\
92\end{array}$ & $\begin{array}{l}47 \\
85\end{array}$ & $\begin{array}{l}59 \\
54\end{array}$ & $\begin{array}{l}65 \\
77\end{array}$ & $\begin{array}{l}71 \\
46\end{array}$ \\
\hline & 64 & 80 & 64 & 71 & 88 & 80 & 62 & 79 & 63 \\
\hline
\end{tabular}

"Presence agreed by two of three observers.

tSitting or supine.

FEF $_{\text {so }}$ FIF $_{\text {so }}$ - see table 1. 
volume curves in one or the other position in eight of 17 patients with sleep apnoea. Four patients showed sawtoothing in both the sitting and the supine posture, one in only the sitting posture, and three in only the supine posture. The sensitivity of this test therefore increased from $29 \%$ to $41 \%$ by recording flow-volume loops in the supine rather than the sitting posture and to $47 \%$ if the results in the two positions were combined. Although less sensitive than $\mathrm{FEF}_{s 0} / \mathrm{FIF}_{50}$ ratio greater than 1, the sawtooth pattern showed higher specificity for obstructive sleep apnoea (table 2).

Those patients with obstructive sleep apnoea who had sawtoothing did not have more severe disease, at least as judged by the number of episodes of apnoea per hour. The maximal fall in oxygen saturation $\left(\Delta \mathrm{SaO}_{2} \%\right)$ during sleep in patients with obstructive sleep apnoea was, however, greater in those with sawtoothing $(35.7 \%$ (SE 6.87\%)) than in those without sawtoothing (13\% (3.4\%)); $\mathrm{p}<0.01)$.

Thus most of our subjects with obstructive sleep apnoea had an abnormality of the flow-volume loop, with either an $\mathrm{FEF}_{s 0} / \mathrm{FIF}_{s 0}$ ratio greater than one or the presence of a sawtooth pattern or both. In 10 of 17 patients with the disease one or other abnormality (or both) occurred in the sitting posture, while there were six false positive results. In the supine posture 11 of 17 had abnormalities in the flowvolume curve, with only three false positive results recorded. Thus with a change from the sitting to the supine posture sensitivity increased from $59 \%$ to $65 \%$, specificity from $54 \%$ to $77 \%$, and the positive predictive value from $62 \%$ to $79 \%$ (table 2 ). If we combined an $\mathrm{FEF}_{s 0} \mathrm{FIF}_{30}$ ratio greater than 1 with the presence of sawtoothing in either the sitting or the supine posture, the sensitivity of the flowvolume loop in screening for sleep apnoea increased from $59 \%$ to $71 \%$. This, however, was at the expense of a fall in specificity to $46 \%$.

\section{Discussion}

This study was designed to investigate whether abnormalities in the flow-volume loop in subjects with obstructive sleep apnoea were detected more frequently in the supine than in the sitting posture.

Sawtoothing in our study had a lower sensitivity for obstructive sleep apnoea than previously reported. Indeed, in the original study ${ }^{2}$ a sensitivity of $85 \%$ and a specificity of $100 \%$ were reported, but in more recent studies sensitivity has varied from $50 \%$ to $60 \% .^{3-6}$ There are three possible explanations for these different findings. Differences in interpretation of flow-volume loops by different readers is probably a factor and other recent studies $^{56}$ support the use of multiple reviewers.
When we examined those cases in which our readers differed in their interpretation, it was evident that different readers used different amplitude thresholds for recognition of the presence of the sign. While differences in the patients studied and the severity of disease might be relevant, our results and those of Haponik ${ }^{4}$ suggest that the sensitivity of the sawtooth pattern is not a function of the severity of disease. Differences in equipment are a further possible reason for the reported differences in sensitivity.

Although the sensitivity of the sign was low its specificity was high in our study, in accord with pre- $\overrightarrow{0}$ vious reports. ${ }^{23}$ Indeed, there were only two patients with false positive results and they were both very of obese. A recent study by Tammelin $e^{t} a^{5}$ showed a 은 specificity of only $71 \%$ for the sawtooth sign because of false positive results in two subjects, both of whom were obese. The high specificity implies $\stackrel{0}{\circ}$ that if sawtoothing is found it is very likely that the $\stackrel{\mathbb{C}}{-}$ subject has obstructive sleep apnoea and that a more $\vec{\oplus}$ detailed evaluation should be done. In addition, $\infty$ unlike Haponik et $a^{6}$ we found greater oxygen desaturation in those patients with obstructive sleep apnoea who had sawtoothing than in those without it.

The second abnormality in the flow-volume loop which we examined was the presence of an $\mathrm{FEF}_{\text {so }} \cong$ FIF $_{50}$ ratio greater than 1 . This abnormality had a $\overrightarrow{0}$ low sensitivity for the diagnosis of obstructive sleep 3 apnoea when measurements were made in the sitting posture-namely $41 \%$, a sensitivity which was similar to that previously reported..$^{1-4}$ The specificity of this abnormality for obstructive sleep apnoea was lower than previously reported, ${ }^{3}$ but this is hardly $x$ surprising as Rotman et $a^{8}$ found this ratio to be greater than 1 in four of 15 normal subjects.

When we examined the combined results-that is, the presence of either sawtoothing or an $\mathrm{FEF}_{50} / \mathrm{FIF}_{50}$ ratio greater than 1 -the greatest sensitivity and $\frac{\text { th }}{2}$ specificity were obtained, and these results were $\rightarrow$ improved by making measurements in the supine posture (table 2). Since, however, the overall fre- N quencies of false positive and false negative results in the supine position were three out of 14 and six out of 17 we do not consider the flow-volume curve $\omega$ an adequate screening test in a patient with sus- -2 pected obstructive sleep apnoea, but because of theo high specificity of sawtoothing its presence is an $\mathbb{D}$ important finding. The greater frequency of abnor-? malities in the supine posture suggests that posture ${ }^{0}$ alone may alter the configuration of the upper air- $\frac{O}{\mathbb{D}}$ way in subjects with obstructive sleep apnoea.

We acknowledge the help of Mr Daniel C Barrett in preparation of this manuscript and $\mathrm{Mr}$ Chris Chung 
for technical assistance. The studies were supported in part by National Institutes of Health Grants HL-08805 and AGO3934 and AG05316.

\section{References}

' Haponik EF, Bleecker ER, Allen RP, et al. Abnormal inspiratory flow-volume curves in patients with sleep-disordered breathing. Am Rev Respir Dis 1981;124:571-4.

${ }^{2}$ Sanders MH, Martin RJ, Pennock BE, Rogers RM. The detection of sleep apnea in the awake patient. JAMA 1981;245:2414-8.

${ }^{3}$ Chaudhary BA, Elguind AS, Giacommini K, Speir WA. Diagnosis of sleep apnea by flow-volume loops. Am Rev Respir Dis 1982;125:101(abstract).

${ }^{4}$ Haponik EF, Smith PL, Bohlman ME, et al. Computerized tomography in obstructive sleep apnea. $A m R e v$ Respir Dis 1983;127:221-6.
5 Tammelin BR, Wilson AF, Borowiecki BB, Sassin JF. Flow-volume curves reflect pharyngeal airway abnormalities in sleep apnea syndrome. Am Rev Respir Dis 1983; 128: 712-5.

${ }^{6}$ Haponik EF, Smith PL, Kaplan J, Bleecker ER. Flowvolume curves and sleep-disordered breathing: therapeutic implications. Thorax 1983;38:609-15.

${ }^{7}$ Suratt PM, Dee P, Atkinson RL, et al. Fluoroscopic and computed tomographic features of the pharyngeal airway in obstructive sleep apnoea. Am Rev Respir Dis 1983; 127:487-92.

${ }^{8}$ Rotman HH, Liss HP, Weg JG. Diagnosis of upper airway obstruction by pulmonary function testing. Chest 1975;68:796-9.

${ }^{9}$ Block AJ, Boysen PG, Wynne JW, Hung LA. Sleep apnea, hypopnea, and oxygen desaturation in normal subjects. N Engl J Med 1979;300:513-7.

${ }^{10}$ Rechtschaffen A, Kales A, eds. $A$ manual of standardized techniques and scoring system for sleep stages of human subjects. Los Angeles: Brain Information Service and Brain Research Institute, 1968. 